\title{
A BUSCA PELA TUTELA JURÍDICA DO DESLOCADO AMBIENTAL E O DIREITO INTERNACIONAL DOS REFUGIADOS
}

\section{André Ricci de Amorim*}

\section{RESUMO:}

O presente trabalho busca refletir sobre as vítimas de deslocamentos forçados no mundo atual a partir das razões que justificam a concessão da proteção internacional, considerando a Convenção das Nações Unidas relativa ao Estatuto dos Refugiados de 1951 e o Protocolo de Nova York de 1967. Em seguida, será abordada a questão do reconhecimento da tutela jurídica ao deslocado ambiental. Por fim, a terceira seção se ocupará de apresentar algumas iniciativas em matéria de proteção ao deslocado ambiental. O presente trabalho utiliza métodos bibliográficos análise de textos da doutrina especializada, bem como convenções internacionais.

PALAVRAS-CHAVE: Migração; Deslocamento Forçado; Refugiados; Convenção das Nações Unidas relativa ao Estatuto dos Refugiados de 1951; Deslocamento Ambiental.

\section{THE PURSUIT FOR LEGAL GUARANTEE OF ENVIRONMENTAL DISPLACED PEOPLE AND INTERNATIONAL REFUGEE LAW}

\begin{abstract}
:
The scope of this paper is a reflection on the victims of forced displacement nowadays according to the reasons for granting international protection, considering the 1951 United Nations Convention on the Status of Refugees and the 1967 New York Protocol. Further, it will be presented the issue of recognition of legal protection to the environmental displaced people. Finally, the third section will deal with presenting some initiatives in terms of protecting environmental displaced people. Certainly, it is worth mentioning that the work uses bibliographic methods such as International Conventions that allow the reader a better perception of the subject.
\end{abstract}

KEY-WORDS: Migration; Forced Displacement; Refugees; the 1951 United Nations Convention on the Status of Refugees; Environmental Displacement.

\section{Introdução}

Ao pensar no progresso da nossa sociedade é impossível dissociá-lo da integração cada vez maior entre Estados e pessoas. Nesse contexto, o fenômeno da mobilidade humana

\footnotetext{
* Doutorando em Direito Internacional na Universidade do Estado do Rio de Janeiro. Mestre em Direito Internacional Público e da União Europeia pela Universidade de Coimbra, Portugal. Bacharel em Direito pela Universidade Federal do Rio de Janeiro. Membro do Grupo de Pesquisa em Direito Internacional da Universidade Federal do Rio de Janeiro. Advogado e Professor Universitário. E-mail: andrericci_8@hotmail.com.
} 
se mostra presente e pode ser causada por inúmeras razões, sejam antropogênicas, naturais ou mistas. Sobre isso, Giddens (2008) atenta para o fato de que esse fenômeno parece acelerar a integração global, mas que ao mesmo tempo pode refletir um lado obscuro, qual seja, ser causado por uma circunstância forçada ou por consequência de um evento traumático.

Contudo, dentre esses indivíduos que migram, os refugiados configuram o grupo mais vulnerável. Em meio a conflitos por motivo de raça, religião, nacionalidade, pertencimento a determinado grupo social ou político, o início da trajetória do refugiado é sempre conturbada. A dificuldade em deixar para trás sua terra, seu lar, sua rotina e tudo que um dia foi tão comum, agora se torna fundamental para sua sobrevivência, segurança e liberdade.

É nesse contexto que o instituto do refúgio serve para cobrir - e assegurar proteção a uma série de situações envolvendo perseguição por motivos de raça, religião, nacionalidade, filiação a um determinado grupo social ou opiniões políticas que vão contra os interesses de grupos de um determinado Estado. Mas até que esse nível de proteção fosse alcançado pelo indivíduo na sociedade internacional, é evidente que a ocorrência de conflitos serviu para alavancar o desenvolvimento da matéria.

A despeito disso, importa ressaltar que nos últimos anos tem se avultado as discussões sobre como o Direito Internacional deve conferir tratamento para esses homens, mulheres e crianças que se deslocam por questões ambientais.

Deste modo, a primeira seção se ocupará em discorrer sobre a tutela jurídica dos refugiados, perpassando por conceitos extraídos da Convenção das Nações Unidas relativa ao Estatuto dos Refugiados de 1951, principal documento em matéria de proteção aos refugiados.

Em seguida, será apresentada a dicotomia presente no Direito Internacional acerca do uso da nomenclatura "refugiado ambiental" como forma de designar o indivíduo que é forçado a se deslocar por razões ambientais.

Por fim, a terceira parte apresentará, ainda que em escassas e em breve síntese, algumas iniciativas em matéria de proteção aos que se deslocam motivados por questões do meio ambiente.

Portanto, o tema do presente trabalho é atual e de interesse geral, visto que, tem se exigido cada vez mais da sociedade internacional medidas que promovam não apenas a proteção imediata, mas soluções duradouras para essas pessoas. Deste modo, se mostra 
fundamental o envolvimento da academia nesta temática a fim de contribuir para a criação de meios de proteção.

\section{Os refugiados no Direito Internacional}

A perseguição por parte dos sujeitos clássicos do Direito Internacional aos indivíduos não é característica exclusiva da contemporaneidade, ao contrário, nos remetem aos tempos antigos (JAEGER, 2001).

No entanto, este instituto surge no contexto de grandes guerras internacionais produzidas no decorrer do século XX, como resultado de disputas territoriais e da necessidade de estabelecer novos marcos fronteiriços que tenham causado vários problemas para a sociedade civil. Com o fim da Primeira Guerra Mundial (1914-1918) foi concebido o projeto de criação da Liga das Nações, que visava criar uma organização intergovernamental de caráter permanente, baseada nos princípios da segurança coletiva e da igualdade entre os Estados.

Desde o início, viu-se que, além de garantir a paz mundial, também era necessário minimizar os danos deixados pelo conflito e encontrar uma maneira de proteger as vítimas que estavam em um verdadeiro limbo jurídico e social.

Durante esse período, as mudanças geográficas dos Estados recém-criados resultaram em um grande número de apátridas e cerca de 1,5 milhão de refugiados e deslocados internos, espalhados por vários países europeus sem qualquer proteção jurídica dos seus Estados de origem (CIERCO, 2010, p. 26-27).

Inicialmente, nada foi feito, em termos práticos, para resolver especificamente a questão dos refugiados. Foi somente em 1921, quando a Liga das Nações foi acionada para ajudar mais de um milhão de refugiados russos deslocados pela Guerra Civil Russa que algo começou a ser delineado de forma mais eficaz (CIERCO, 2010, p. 33).

Assim, o Doutor Fridtjof Nansen foi designado como Alto Comissário para tratar da questão dos refugiados russos, bem como o êxodo de quase 2 milhões de pessoas afetadas pela Guerra Greco-Turca de 1919-1922 (FELLOWS, 2012, p. 106).

Apesar dos esforços empreendidos pela Liga das Nações, tal organização não foi bem sucedida em sua tentativa de promover a paz entre os Estados e um conflito ainda maior não foi evitado, qual seja, a Segunda Guerra Mundial. Portanto, foi a partir daí que foi 
possível delinear, em termos globais, a definição do instituto do refúgio a fim de assegurar a proteção às milhares de vítimas que se deslocavam internamente na Europa.

De plano, não seria possível olvidar que a primeira tentativa da sociedade internacional de codificar uma espécie de direito de refúgio pode ser percebida na Declaração Universal dos Direitos Humanos (DUDH), adotada em 10 de dezembro de 1948, em especial, no artigo 14(1) que menciona que "toda a pessoa sujeita a perseguição tem o direito de procurar e de beneficiar de asilo noutros países".

No entanto, por não especificar o destinatário, tal documento restou padecendo de eficácia e, consoante exegese de Goodwin-Gill e McAdam (2007, p. 172), não foi bastante para garantir a proteção dos refugiados, pois os Estados não demonstraram através de ações práticas sua intenção em assumir uma obrigação moral no sentido de reverter a situação dessas pessoas.

Assim, foi preciso pensar em maneiras mais empíricas para resolver a questão do refúgio. Neste contexto, a Organização das Nações Unidas (ONU) surgiu com o propósito de engendrar medidas para alcançar a paz mundial ao mesmo tempo em que buscava minimizar os efeitos do pós-guerra. Por conseguinte, foi criada a agência da ONU voltada para atender especificamente os refugiados: o Alto Comissário das Nações Unidas para os Refugiados (ACNUR).

Ocorre que, mesmo com o passar das décadas, a questão do refúgio continuou - e ainda continua - pungente em nossa sociedade. Hodiernamente, tem-se observado que estas vítimas de perseguição acabam sendo enquadradas, erroneamente, pela sociedade como típicos migrantes que saem de seus países por livre e espontânea vontade a fim de construir uma vida melhor no exterior. Por essa razão, pretende-se apresentar nesta seção, ainda que em apertada síntese, o desenvolvimento do conceito jurídico do instituto refúgio.

Ora, em se tratando do referido instituto insta ressaltar dois importantes instrumentos internacionais, quais sejam: a Convenção das Nações Unidas relativa ao Estatuto dos Refugiados de 1951 - ora referida simplesmente como Convenção de Genebra de 1951 - e o Protocolo Adicional de Nova York de 1967 - ora Protocolo de 1967. O dispositivo fulcral que define a quem será aplicado o termo "refugiado" é o artigo $1^{\circ}(\mathrm{A})(2)$ da Convenção de 1951. Senão, veja-se: 
[T] emendo ser perseguida por motivos de raça, religião, nacionalidade, grupo social ou opiniões políticas, se encontra fora do país de sua nacionalidade e que não pode ou, em virtude desse temor, não quer valer-se da proteção desse país, ou que, se não tem nacionalidade e se encontra fora do país no qual tinha sua residência habitual em consequência de tais acontecimentos, não pode ou, devido ao referido temor, não quer voltar a ele (ALTO COMISSARIADO DAS NAÇÕES UNIDAS PARA OS REFUGIADOS, 1951).

No ponto, mister se faz destacar que o propósito inicial desta Convenção era proteger apenas as vítimas dos acontecimentos ocorridos antes de $1^{\circ}$ de janeiro de 1951, noutros termos, as vítimas da Segunda Guerra Mundial. Por tal razão, na medida em que os anos foram passando e novos conflitos surgiram, a definição de refugiados tornou-se extremamente oblíqua (TRINDADE et al., 1996, p. 267-268).

Diante de tal realidade, o Protocolo de 1967 foi medular para retirar as reservas geográfica e temporal que se faziam presentes na Convenção de Genebra de 1951.

No que tange à natureza jurídica do ato de reconhecimento da condição de refugiado, observa-se o firmamento da posição doutrinária de que o indivíduo se torna refugiado a partir do momento em que satisfizer os critérios estabelecidos na Convenção de Genebra de 1951, sendo, portanto, um ato de natureza declaratória (GOODWIN-GILL; MCADAM, 2007, p. $51)$.

Ademais, sob o enfoque das garantias asseguradas aos refugiados na referida Convenção, destacam-se a aplicação do princípio do non-refoulement, a proibição de perseguição criminal e a temporariedade da concessão do asilo.

A primeira delas informa que será expressamente vedada a transferência do refugiado para o seu país de origem ou de residência habitual enquanto permanecerem as circunstâncias que põem em risco sua vida, integridade física e liberdade. Ao ensejo, a doutrina assevera que tal direito constitui um princípio geral do Direito Internacional de proteção dos refugiados e dos direitos humanos (GOODWIN-GILL; MCADAM, 2007). Vejamos o que informa o artigo 33(1) da Convenção de 1951:

Artigo 33.

1. Nenhum dos Estados Contratantes expulsará ou rechaçará, de maneira alguma, um refugiado para as fronteiras dos territórios em que a sua vida ou a sua liberdade seja ameaçada em virtude da sua raça, da sua religião, da sua nacionalidade, do grupo social a que pertence ou das suas opiniões políticas (ALTO COMISSARIADO DAS NAÇÕES UNIDAS PARA OS REFUGIADOS, 1951). 
Ao longo de sua pesquisa, Goodwin-Gill e McAdam (2007) ressaltam que o refoulement assume caráter próprio de modo que não seria cabível tratá-lo como sinônimo dos institutos da expulsão ou deportação, processos mais formais pelos quais um estrangeiro pode ser retirado do Estado compulsoriamente.

Ademais, insta mencionar que a aplicação do non-refoulement não é ilimitada. Vide, pois, o artigo 33(2) da Convenção de 1951, que informa não ser possível invocar o benefício quando o refugiado for considerado perigoso para a segurança do país no qual esteja ou ser condenado por crime grave com sentença transitada em julgado e, por isso, passa a representar um risco para a segurança local.

É neste sentido que o jurista Jacob Dolinger (2008) entende que somente será admitida a saída compulsória do refugiado através do instituto da expulsão, caso este traga risco para a segurança nacional ou ordem pública. Por outro lado, o autor assevera que o Estado deve garantir o direito do refugiado a apresentar sua defesa em tempo suficiente para encontrar outro país que queira abrigá-lo.

Por conseguinte, a garantia de proibição de perseguição criminal é plasmada no artigo 31(1) da Convenção de 1951. In verbis:

\footnotetext{
Artigo 31.

1. Os Estados Contratantes não aplicarão sanções penais em virtude da sua entrada ou permanência irregulares, aos refugiados que, chegando diretamente do território no qual sua vida ou sua liberdade estava ameaçada no sentido previsto pelo art. $1^{\mathrm{o}}$, cheguem ou se encontrem no seu território sem autorização, contanto que se apresentem sem demora às autoridades e lhes exponham razões aceitáveis para a sua entrada ou presença irregulares (ALTO COMISSARIADO DAS NAÇÕES UNIDAS PARA OS REFUGIADOS, 1951).
}

Ao analisar o artigo em comento, nota-se uma tentativa e mitigar a conduta do refugiado que, ao deixar o seu país de origem, não encontrou condições viáveis para cumprir os trâmites administrativos e/ou burocráticos de ingresso noutro Estado, tais como a solicitação de um passaporte, o requerimento de visto de ingresso, a reserva da hospedagem, dentre outros. Isso porque, geralmente o refugiado não tem muito tempo para planejar a sua viagem e esta conduta de retirada imediata foi a forma encontrada de preservação da sua própria vida.

Sobre isso, em oportuno escólio sobre o tema, Hathaway (1991) ressalta que a Convenção de Genebra de 1951 não condicionou a análise do pedido de reconhecimento da condição de refugiado a entrada regular do refugiado no território do Estado, mas reconhece 
que em razão da dificuldade em interpretar tal artigo, agentes do Estado precisam fazer uma verificação, in casu, se o indivíduo preenche os requisitos da presente Convenção.

Por fim, a terceira salvaguarda da Convenção de Genebra de 1951 que merece destaque é a temporariedade da concessão do refúgio. Isso quer dizer que, mesmo obtendo o reconhecimento da condição de refugiado, tal situação deve ser entendida como aplicável somente enquanto durarem as razões que causaram a saída do território. Assim, a doutrina tem entendido que no caso dos refugiados, o ideal seria a aplicação da repatriação voluntária, ou seja, o retorno dessas pessoas aos seus Estados de origem ou de residência habitual a partir do momento em que a situação voltar à normalidade, já que após o fim da perseguição a proteção internacional perderia o seu propósito (GILBERT, 1998).

Em meio a grande demanda mundial em encontrar solução duradoura para a questão dos refugiados, existem pleitos sobre a mudança ou evolução deste conceito.

Deste modo, é possível notar que embora a Convenção de Genebra de 1951 tenha sofrido alteração ao longo dos anos, nada se firmou no sentido de estabelecer qualquer relação entre a mobilidade humana forçada e o meio ambiente. Isso nos leva ao problema deste trabalho: seria possível reconhecer os deslocados ambientais como "refugiados ambientais" e conferir-lhes a mesma proteção jurídica albergada pela Convenção de 1951 ?

\section{A dicotomia entre refúgio e deslocamento ambiental}

Muito embora a Convenção de Genebra de 1951 não associe o deslocamento forçado com questões ambientais, não se pode negar que, em determinadas situações, é possível traçar tal liame. Deste modo, corroboramos com o entendimento de Castles (2002, p. 3) que ressalta que a desertificação, a escassez e o aumento do nível da água são alguns dos fenômenos ambientais que contribuem para o aumento do fluxo de deslocamento forçado em determinadas regiões, tais como em Bangladesh, Vietnam, Gana e Etiópia.

Não obstante, seria imprudente deixar de registrar que ao discorrer sobre migrações humanas motivadas por questões ambientais, nos deparemos, frequentemente, com o termo "refugiado ambiental". Assim é que impende mencionar que tal nomenclatura foi citada pela primeira vez por Lester Brown, pesquisador do World Watch Institute, ainda na década de 1970. No entanto, sua notoriedade e disseminação somente ganharam impulso a partir da 
publicação dos trabalhos dos professores Essam El-Hinnawi, do Egyptian National Research Center, em 1985; e, posteriormente, Jodi Jacobson, em 1988 (BLACK, 2001, p.1).

Na definição concebida por Myers e Kent (1995, p. 18), "refugiados ambientais" são pessoas que não conseguem mais viver em segurança no seu local de origem em razão de fatores ambientais, tais como mudanças climáticas e desastres ambientais.

Nesta senda, tem sido pontuado pela doutrina que os movimentos migratórios por razões ambientais podem ocorrer basicamente por três razões, quais sejam: $i$ ) antropogênicas, ou seja, quando é causada pela própria ação do ser humano; ii) naturais, quando se dá em razão de eventos ambientais sem interferência humana; e iii) mistas, quando, “concomitantemente e em graus diversos, a migração [foi] motivada por situações ambientais adversas que impedem ou dificultam a vida humana em determinado espaço geográfico" (CLARO, 2018, p. 69).

De fato, partindo da análise estrita do texto da Convenção de Genebra de 1951 sobre a definição do termo "refugiado", bem como considerando as normas de Direito Internacional, existe uma grande dificuldade doutrinária, senão impossibilidade, de tornar correto o uso da nomenclatura "refugiado ambiental", uma vez que não se trata de perseguição motivada por razões de raça, religião, nacionalidade, grupo social ou opiniões políticas, conforme previsto no artigo $1^{\circ}$ do referido documento internacional.

A despeito de alguns preceptores defedenderem o uso do referido termo, a par de amainar as divergências, o Alto Comissariado das Nações Unidas para os Refugiados já se manifestou acerca do uso da nomenclatura "refugiado ambiental". Portanto, veja-se, pois, o verbete deste órgão:

\footnotetext{
Nos últimos tempos, um número crescente de organizações e comentaristas empregou a noção de "refugiados ambientais" ou "refugiados climáticos", um conceito usado para se referir a pessoas que são obrigadas a deixar seu local de residência habitual como resultado de mudanças climáticas de longo prazo ou desastres naturais repentinos. O ACNUR tem sérias reservas em relação à terminologia acerca da noção de refugiados ambientais ou climáticos. Esses termos não têm fundamento no Direito Internacional dos Refugiados (ALTO COMISSARIADO DAS NAÇÕES UNIDAS PARA OS REFUGIADOS, 2009, p. 8 - tradução livre) ${ }^{1}$.
}

\footnotetext{
${ }^{1}$ Em inglês, o texto original é: "In recent times, a growing number of organizations and commentators have employed the notion of 'environmental refugees' or 'climate refugees,' a concept used to refer to people who are obliged to leave their usual place of residence as a result of long-term climate change or sudden natural disasters. UNHCR has serious reservations with respect to the terminology and notion of environmental refugees or climate refugees. These terms have no basis in international refugee law" (ALTO COMISSARIADO DAS NAÇÕES UNIDAS PARA OS REFUGIADOS, 2009)
} 
Por tal razão, a corrente majoritária tem optado por se referir a esse grupo de pessoas que se desloca por questões ambientais como "deslocados ambientais" ao invés de "refugiados ambientais". Isso porque, reiterando o que foi dito anteriormente, não lhes é garantido o reconhecimento da condição de refugiado pelos termos da Convenção de Genebra de 1951.

Averbe-se, ainda, a discussão quanto ao uso do termo "deslocado" em detrimento da nomenclatura "migrante". Sobre isso, entendemos mais adequado o uso do primeiro termo, pois vai de encontro ao que Oakes et al. (2016, p. 19) disseram sobre o fato de a migração inferir certo grau de escolha em como e quando se mover, enquanto o deslocamento traz a ideia de ser algo forçado, pois significa que as pessoas foram expulsas de suas casas por eventos ambientais isolados ou repetidos.

Com efeito, Pentinat (2006, p.92) aduz que os Estados tendem a não alargar a interpretação da referida Convenção por entenderem que isso potencializaria o enfraquecimento da proteção aos refugiados, uma vez que o deslocamento por razão ambiental é situação excepcional.

Delineadas tais considerações acerca da dificuldade em reconhecer o deslocado ambiental como refugiado à luz do Direito Internacional, Jubilut (2007, p. 168) enuncia que, embora vulneráveis, não há qualquer documento internacional a nível global que proteja de forma específica o referido grupo.

No entanto, insta trazer à baila que enquanto não se encontra uma solução duradoura em matéria de migração por questão ambiental, o paládio gozado por essas pessoas é assegurado através de um sistema de proteção complementar baseado em tratados internacionais de direitos humanos e princípios gerais de direito humanitário (MCADAM, 2005, p.1).

Ao escrutinar a experiência brasileira, é possível notar que o nosso país aplicou tal sistema de proteção complementar aos haitianos que chegaram principalmente após o terremoto que abalou o país em 2010.

Através da Resolução Normativa No 97/2012, do Conselho Nacional de Imigração (CNIg), foi estabelecida a concessão anual de 1.200 (mil e duzentos) vistos humanitários aos haitianos (BRASIL, 2012). Ocorre que, em razão da alta demanda, essa limitação anual na emissão de vistos implicou na entrada irregular em território nacional de milhares de haitianos 
e só foi extinta após o transcurso de pouco mais de 1 (um) ano, por intermédio da edição da Resolução Normativa No 102/2013.

Isso demonstra que a demora da resposta estatal e a ausência de um instrumento jurídico normativo de proteção específica ao deslocado ambiental são fatores que podem agravar ainda mais a situação de vulnerabilidade dessas pessoas.

No que tange a concessão dos vistos de caráter humanitário, há de se atentar que, por se tratar de ato do Poder Executivo, a expectativa de proteção jurídica também pode ser abalada e não se mostrar tão eficaz. Isso porque eles podem sofrer alguma alteração, expirar ou até mesmo serem revogados, dependendo da vontade política do governo (JUBILUT et al., 2016, p. 78).

Para além dos efeitos comentados, ao esmiuçar a capilaridade do tema, nota-se que, consoante elucubrações de O’Brian et al. (2006), as consequências de um desastre ambiental são proporcionalmente mais agravados em locais cujo poder econômico é mais precário. Assim, além de os mais pobres estarem mais propícios a sofrerem com os efeitos de um desastre ambiental, caso sejam atingidos e se vejam forçados a saírem de seus países, ainda se debruçam diante da situação de vulnerabilidade jurídica em razão da ausência de um instrumento específico que garanta a sua proteção enquanto deslocado ambiental.

Ante tal realidade, a próxima seção intende discorrer sobre alguns instrumentos jurídicos que já asseguram um tratamento diferenciado aos deslocados por questões ambientais. Confiramos.

\section{Iniciativas relevantes em matéria de deslocamento ambiental}

Neste excerto, merece destacar dois instrumentos regionais de proteção no qual a temática do deslocamento ambiental está inserida. O primeiro é a Convenção sobre a Regulação do Status dos Refugiados no Mundo Árabe, adotada em 1994, pela Liga dos Estados Árabes, que reconhece expressamente o status de refugiado a vítimas de desastres naturais ou eventos graves ocorridos em todo o país ou em qualquer parte dele. Todavia, reforça-se que mesmo depois de tantos anos, a Convenção continua sem eficácia 
internacional/regional por não ter atingido o número mínimo de ratificações dos EstadosMembros da Liga Árabe 2 .

Além do documento supracitado, o segundo instrumento internacional a ser aduzido é a Convenção da União Africana sobre a Proteção e Assistência a Pessoas Deslocadas Internamente em África - também chamada de Convenção de Kampala e adotada em 2009. Tal documento reconhece, em seu artigo $1^{\circ}$, que desastres naturais ou provocados pelo homem podem ensejar o deslocamento forçado de pessoas. No entanto, é importante considerar que a referida Convenção se aplica apenas a pessoas deslocadas nos países membros da União Africana (ALTO COMISSARIADO DAS NAÇÕES UNIDAS PARA OS REFUGIADOS, 2009).

Isso demonstra que, ainda que seja encampada a corrente tradicionalista que inviaviliza o reconhecimento do deslocado ambiental como refugiado, é possível considerar que tratados internacionais de alcance regional podem servir como balizadores da proteção a esse grupo em vulnerabilidade.

Assim, embora muito já se tenha avançado como, por exemplo, ao reconhecer que em algumas circunstâncias existe uma interação entre mobilidade humana e alterações no meio ambiente, não se pode olvidar de que a sociedade internacional ainda precisa prosseguir na busca por soluções duráveis.

Ademais, cabe ressaltar que em razão da não inclusão do deslocado ambiental no rol de refugiados da Convenção de Genebra de 1951, tal grupo não pode contar com a garantia de não devolução por parte do Estado receptor, em outras palavras, não seria aplicável, a priori, o princípio do non-refoulement.

Portanto, por serem classificados como estrangeiros comuns, os deslocados ambientais tem a sua proteção fragilizada em razão da discricionariedade do Estado. Assim, há autores que sustentam a urgência do reconhecimento jurídico específico dessa categoria a fim de proporcionar os meios mais efetivos de assistência (GUERRA, 2018, p. 164-165).

A par de amainar este cenário, Cavedon et al. (2018) ressaltam que no âmbito da responsabilidade internacional dos Estados já existe um projeto que visa assegurar proteção

\footnotetext{
${ }^{2} \mathrm{O}$ artigo 1(2) desse instrumento informa que será reconhecido como refugiado: "any person who unwillingly takes refuge in a country other than his country of origin or his habitual place of residence because of sustained aggression against, occupation and foreign domination of such country or because of the occurrence of natural disasters or grave events resulting in major disruption of public order in the whole country or any part thereof" (ALTO COMISSARIADO DAS NAÇÕES UNIDAS PARA OS REFUGIADOS, 1994).
} 
específica aos deslocados ambientais: o Projeto de Convenção de Limoges sobre o Estatuto Internacional dos Deslocados Ambientais. Os autores ressaltam que o referido Projeto “apresenta uma proposta de marco institucional para a gestão dos deslocamentos ambientais através da criação de organismos específicos: Agência Mundial para os Deslocados Ambientais, Alta Autoridade e Fundo Mundial para os Deslocados Ambientais" (CAVEDON et al., 2018, p. 217).

Ora, ainda que na prática seja difícil vislumbrar um documento internacional em matéria de proteção ao deslocado ambiental tal qual aquele apresentado por Cavedon et al., reforça-se a importância de se começar a pensar no desenvolvimento de um instrumento regional ou nacional. Isso porque, não custa salientar que a discussão desse tema no Brasil - e alhures - é atual e de extrema relevância, pois estamos cercados por países cuja população sofre grandes efeitos em razão de questões ligadas ao clima e meio ambiente, tais como Equador, Peru, Venezuela e Colômbia e que, portanto, poderiam gerar movimentos migratórios na região (KHAMIS; OSORIO, 2013).

No contexto latino-americano, por exemplo, a Lei de Mobilidade Humana do Equador garante expressamente, em seu Artigo 58, a concessão de vistos humanitários às pessoas que sofrem por desastres naturais ou ambientais sem citar um número mínimo de vistos que o Estado emitirá (REPÚBLICA DO EQUADOR, 2017). Ainda que tal disposição seja relevante, não ainda esbarra na problemática apontada anteriormente por Jubilut et al. (2016, p. 78).

Diante do atual cenário, um tema que se propõe discutir a inter-relação entre meio ambiente, mobilidade humana, Direito Internacional e Direitos Humanos, se mostra atual e contributivo para avanços sobre a construção de (novos) meios de proteção aos deslocados ambientais. No âmbito regional, por exemplo, isso poderia ser de grande valia, conforme sugerido por Ramos et al (2017), para o desenvolvimento de um tratado regional em matéria de deslocamento ambiental.

Ressalte-se, todavia, que não há qualquer perspectiva de que a criação de um instrumento jurídico próprio, seja em nível regional ou internacional, será suficiente para garantir efetivamente a proteção necessária aos deslocados ambientais.

$\mathrm{Na}$ verdade, entendemos que essa poderia ser uma das formas adequadas, embora não exígua, uma vez que a norma jurídica, por si só, não é capaz de atender os anseios da sociedade, já que sempre depende de um conjunto de valores que impera em uma sociedade 
concreta (FLORES, 2008, p. 34-35). No que tange ao reconhecimento da condição de refugiado ao deslocado ambiental, vale lembrar as considerações apontadas Squeff ao dizer que:

\begin{abstract}
[o reconhecimento] serviria não apenas para oferecer uma tutela jurídica específica àqueles que se encontram fora do seu país de origem e/ou nacionalidade na tentativa de diminuir a vulnerabilidade na qual eles se encontram, mas funcionaria igualmente enquanto uma possibilidade de romper com a lógica eurocêntrica que ainda permeia o Direito Internacional, destacando a possibilidade de outras localidades também reagirem "ativa e altivamente" às consequências da contemporaneidade, tal como são os efeitos das mudanças climáticas, apontando o arcabouço jurídico específico a ser designado a esses indivíduos, o qual é inclusivo e realmente preocupado com o ser humano, independentemente da sua procedência, em detrimento da sua consideração enquanto "mero" estrangeiro (SQUEFF, 2018, p. 238).
\end{abstract}

Em todo caso, não se espera que um único documento ponha fim a vulnerabilidade destas pessoas. Fosse assim, a Convenção de Genebra de 1951 teria sido capaz de garantir solução duradoura para a questão dos refugiados, o que, infelizmente, não o fez.

Isto posto, o tema se mostra atual e de grande relevância, pois se estima que o número de pessoas nesta condição até 2050 poderá ser de 200 milhões até 1 bilhão no mundo (KING, 2010, p. 72).

\title{
5. Considerações finais
}

À luz do Direito Internacional dos Refugiados garantido principalmente na Convenção das Nações Unidas relativa ao Estatuto dos Refugiados de 1951 e no Protocolo Adicional de Nova York de 1967, ficou sobejamente demonstrado que o instituto do refúgio, como alternativa de manutenção e proteção da vida, tem se mostrado presente entre os povos, mormente pela eclosão de guerras, graves crises políticas, intolerância étnica, perseguição religiosa e/ou por pertencimento a determinado grupo. Ante a vulnerabilidade dessas pessoas, tal instituto visa proteger e minimizar as consequências das fortes violações de direitos humanos às quais estão sujeitas.

Ocorre que, conforme mencionado ao longo do trabalho, até o presente momento existe uma tendência no Direito Internacional a não expandir o conceito de refugiado, de sorte a não contemplar a proteção dos deslocados ambientais nos termos da Convenção de 1951. Ressalte-se que a questão acaba assumindo uma faceta mais dramática em razão da ausência de instrumento específico de proteção a esse grupo. 
Deste modo, o presente trabalho propõe que a sociedade internacional atente para alguns aspectos, tais como: $i$ ) a adoção de políticas públicas capazes de reduzir o risco de desastres ambientais, já que os locais mais pobres tendem a sofrer mais com os seus efeitos; e ii) a necessidade de discussão acerca da viabilidade de construção de - novos - meios de proteção ao deslocado ambiental, em especial, a criação de um instrumento específico de proteção, ainda que a nível regional, conforme observado nos documentos da Liga Árabe e da União Africana.

Portanto, eis lançado o desafio: preparemo-nos para essa empreitada na implementação de um instrumento jurídico que sistematize a relação entre mobilidade humana e o meio ambiente, de sorte a que se possa, enfim, evoluir o método de tutela jurídica ao deslocado ambiental, não deixando a cargo somente da proteção complementar baseada em tratados internacionais de direitos humanos e princípios gerais de direito humanitário.

\section{Referências bibliográficas}

ALTO COMISSARIADO DAS NAÇÕES UNIDAS PARA OS REFUGIADOS. African Union Convention for the Protection and Assistance of Internally Displaced Persons in Africa (2009). Disponível em: <https://www.unhcr.org/aboutus/background/4ae9bede9/african-union-convention-protection-assistance-internallydisplaced-persons.html>. Acesso em: 11 Jul. 2019.

Arab Convention on Regulating Status of Refugees in the Arab Countries (1994). Disponível em: <http://www.refworld.org/docid/4dd5123f2.html>. Acesso em: $11 \mathrm{Jul}$. 2019.

\footnotetext{
. Climate change, natural disasters and human displacement: a UNHCR $\begin{array}{lllll}\text { perspective, } & 2009, & \text { p. } & 8 . & \text { Disponível }\end{array}$ <http://www.refworld.org/docid/4a8e4f8b2.html\#_ga=1.142270706.1503118157.1485366719 >. Acesso em: 16 Out. 2019.
}

Convenção Relativa ao Estatuto dos Refugiados de 1951. Disponível em: <http://www.acnur.org/t3/fileadmin/Documentos/portugues/BDL/Convencao_relativa_ao_Est atuto_dos_Refugiados.pdf>. Acesso em: 03 Out. 2019.

Protocolo Adicional de 1967 Relativo ao Estatuto dos Refugiados. Disponível em:

<http://www.acnur.org/fileadmin/Documentos/portugues/BD_Legal/Instrumentos_Internacio nais/Protocolo_de_1967.pdf>. Acesso em: 03 Out. 2019. 
BLACK, R. Environmental Refugees: myth or reality? In: New Issues in Refugee Research, United Nations High Commissioner for Refugees. Working Paper n. 34, 2001, pp. 1-20.

BRASIL. Conselho Nacional de Imigração. Resolução Normativa $\mathbf{n}^{\mathbf{0}}$ 97, de 12 de janeiro de $2012 . \quad$ Disponível em: <https://www.diariodasleis.com.br/busca/exibelink.php?numlink=225206>. Acesso em: 04 Nov. 2019.

CASTLES, S. Environmental change and forced migration: making sense of the debate. In: New Issues in Refugee Research, United Nations High Commissioner for Refugees. Working Paper n. 70, 2002.

CAVEDON, F. S.; PRIEUR, M.; LAVIEILLE, J. M. O Projeto de Convenção de Limoges sobre o Estatuto Internacional dos Deslocados Ambientais. In: JUBILUT, L. L; RAMOS, E. P.; CLARO, C. A. B. CAVEDON-CAPDEVILlE, F. S.. (Org.). Refugiados Ambientais. 1ed. Boa Vista: Editora da UFRR, 2018, v. 1, p. 198-229.

CIERCO, T. A instituição de asilo na União Europeia. Coimbra: Almedina, 2010.

CLARO, C. A. B.. O Conceito de Refugiado Ambiental. In: JUBILUT, Liliana Lyra; RAMOS, Érika Pires; CLARO, Carolina de Abreu Batista; CAVEDON-CAPDEVILLE, Fernanda de Sales (Org.). Refugiados Ambientais. $1^{a}$ Ed. Boa Vista: Editora da Universidade Federal de Roraima, 2018, v. 1, p. 69-100.

DOLINGER, J. Direito Internacional Privado: parte geral, 9a Edição. Rio de Janeiro: Renovar, 2008.

FELLOWS, N. History for the IB Diploma: Peacemaking, Peacekeeping: International Relations 1918-36. Cambridge, UK: Cambridge University Press, 2012.

FLORES, J. H. La Reinvención de los Derechos Humanos. Atrapasueños: Sevilla, 2008.

GIDDENS, A. Sociologia, $6^{a}$ edição. Tradução de Alexandra Figueiredo; Ana Patrícia Duarte Baltazar; Catarina Lorga da Silva; Patrícia Matos e Vasco Gil. Coordenação e revisão científica de José Manuel Sobral. Tradução do original inglês intitulado SOCIOLOGY 4'h Edition. Lisboa: Fundação Colouste Gulbenkian, 2008.

GILBERT, G. Rights, Legitimate Expectations, Needs and Responsibilities: UNHCR and the New World Order. International Journal of Refugee Law. Vol. 10; pp. 350-388. Oxford: Oxford University Press, 1998.

GOODWIN-GILL, G. S.; MCADAM, J. The refugee in International Law, $3^{\text {a }}$ Edição, Coleção Clarendon Paperbacks. Oxford, UK: Oxford University Press, 2007.

GUERRA, S. O Sistema Interamericano de Proteção dos Direitos Humanos e o Controle de Convencionalidade, $2^{\text {a }}$ Edição. Curitiba: Instituto Memória, 2019. 
HATHAWAY, J. C. The Law of Refugee Status. Toronto: Butterworths, 1991.

JAEGER, G. On the history of the international protection of refugees. In: International Review of Red Cross, Setembro, Volume 83, no 843, 2001, pp. 727-738. Disponível em: <https://www.icrc.org/eng/assets/files/other/727_738_jaeger.pdf>. Acesso em 28 Set. 2019.

JUBILUT, L. L. O Direito internacional dos refugiados e sua aplicação no ordenamento jurídico brasileiro. São Paulo: Método, 2007.

JUBILUT, L. L.; ANDRADE, C. S. M.; MADUREIRA, A. L. Humanitarian visas: building on Brazil's experience. Forced Migration Review, v. 53, p. 76-78, 2016. Disponível em: $<$ http://www.fmreview.org/community-protection/jubilut-andrade-madureira.html $>$. Acesso em: 14 Nov. 2019.

KHAMIS, M.; OSORIO, C. América del Sur: Una visión regional de la situación de riesgo de desastres. UE-Ayuda Humanitaria y Protección Civil y Oficina de las Naciones Unidas para la Reducción de Riesgo por Desastres. Panamá: UNISDR, 2013, p. 28-43.

KING, R. The Atlas of Human Migration: global patterns of people on the move. London: Earthscan, 2010.

MCADAM, J. Complementary protection and Beyond: how States deal with human rights protection. United Nations High Commissioner for Refugees. Working Paper n. 118, 2005, pp. 1-21.

MYERS, N.; KENT, J. Environmental Exodus: An Emergent Crisis in the Global Arena. Washington DC: Climate Institute, 1995.

OAKES, R.; MILAN, A.; CAMPBELL, J. Kiribati: Climate change and migration Relationships between household vulnerability, human mobility and climate change, (Report N. 20). Bonn: United Nations University Institute for Environment and Human Security (UNU-EHS), 2016.

O'BRIEN, G.; O'KEEFE, P.; ROSE, J.; WISNER, B. Climate change and disaster management. Oxford: Blackwell, 2006.

PENTINAT, S. B. Refugiados Ambientales: el nuevo desafío del Derecho Internacional del medio ambiente. In: Revista Derecho, vol. XIX, n. 2, Diciembre/2006, p. 85-108.

RAMOS, E. P.; CAVEDON, F.; YAMAMOTO, L.; SERRAGLIO, D. Towards a regional agreement on environmental displacement? In: Forced Migration Review, v. 56, p. 65-66, 2017.

REPÚBLICA DO EQUADOR. Ley Orgánica de Movilidad Humana, de 28 de Enero de 2017. Disponível em: <https://www.acnur.org/fileadmin/Documentos/BDL/2017/10973.pdf>. Acesso em: 10 Abr. 2020. 
SQUEFF, T. A. F. R. C. Superando a Colonialidade do Saber no Direito Internacional: o exemplo dos refugiados Ambientais. In: VEDOVATO, L. R.; SQUEFF, T. C. (Org.). Direito Internacional II. 1 ed. Florianópolis: CONPEDI, 2018, v. 1, p. 229-244.

TRINDADE, A.A.C.; PEYTRIGNET, G.; SANTIAGO, J.R. As Três vertentes da Proteção Internacional dos Direitos da Pessoa Humana. San José da Costa Rica: IIDH, Comitê Internacional da Cruz Vermelha, Alto Comissariado das Nações Unidas para os Refugiados, 1996. 